\title{
夏季舟山渔场及邻近海域浮游动物群落结构特征分析
}

\author{
陈小庆 ${ }^{1}$, 陈 斌 ${ }^{2}$, 黄 备 $^{3}$, 王婕妤 ${ }^{3}$, 郑 基 ${ }^{1}$, 宁 平 ${ }^{1,4}$, 俞存根 ${ }^{1}$ * \\ (1. 浙江海洋学院 水产学院, 浙江 舟山 316004; 2. 舟山市海洋与渔业局, 浙江 舟山 316004; 3. 浙江省舟山海洋生态环境监测站, \\ 浙江 舟山 316004; 4. 国家海洋局第二海洋研究所, 浙江 杭州 310012)
}

摘要: 2006 年 8 月在舟山渔场及邻近海域 $\left(29^{\circ} 30^{\prime} \sim 31^{\circ} 30^{\prime} \mathrm{N}, 124^{\circ} 30^{\prime} \mathrm{E}\right.$ 以西) 开展海洋生态系统综合调查, 用浅水 I 型浮游生物网采集的浮游动物样本, 对该海域浮游动物的种类组成、数量分布、生物多样性等群落结构 特征进行了分析。结果得知, 在调查海域共鉴定出浮游动物 93 种 (不包含浮游幼虫), 其中以桡足类的种类数为 最多, 有 50 种, 优势种主要有精致真刺水蚤（Euchaeta concinna）、软拟海樽（Dolioletta gegenbauri）、肥胖箭虫 (Sagitta enflata)、百陶箭虫（Sagitta bedoti）、中华哲水蚤（Calanus sinicus）、普通波水蚤（Undinula vulgaris）、 微刺哲水蚤 (Canthocalanus paupe)、长尾类幼虫（Macruran larvae）、双生水母 (Diphyes chamissonis)、背针胸 刺水蚤 (Centropages dorsispinatus)、肥胖三角溞（Evadne tergestina）、太平洋纺锤水蚤（Acartia pacifica）等 12 种。调查海域浮游动物丰度平面分布呈现南部高、北部低, 近岸高、外海低的特征。生物多样性分析表明, 调查 海域浮游动物种类数较多, 且具有较高的均匀度 (0.70), 因此其生物多样性指数较高 (4.98)。根据聚类分析结 果, 可将夏季调查海域的浮游动物在 $17.13 \%$ 相似性水平上分为 $\mathrm{A} 、 \mathrm{~B} 、 \mathrm{C}$ 三个组群。生物一环境匹配分析显示, 浮游动物的丰度除了与表层盐度、硝酸氮和硅酸盐含量有关外, 还与镉、铅的含量存在着一定相关性。

关键词: 浮游动物; 群落结构; 聚类分析; 舟山渔场及其邻近海域; 夏季

中图分类号: Q958.8 文献标识码: A 文章编号: 0254-5853-(2010)01-0099-09

\section{Analysis on Community Structure of Zooplankton in Zhoushan Fishing Ground and Its Adjacent Area in Summer}

\author{
CHEN Xiao-Qing ${ }^{1}, \mathrm{CHEN} \mathrm{Bin}^{2}$, HUANG Bei ${ }^{3}$, WANG Jie-Yu ${ }^{3}$, \\ ZHENG Ji ${ }^{1}$, NING Ping ${ }^{1,4}$, YU Cun-Gen ${ }^{1, *}$ \\ (1. Fishery College, Zhejiang Ocean University, Zhoushan 316004, China; \\ 2. Zhoushan Marine and Fishery Bureau, Zhoushan 316004, China; \\ 3. Zhoushan Marine Ecological Environment Monitoring Station, Zhoushan 316004, China; \\ 4. Second Institute of Oceanography, State Oceanic Administration, Peoples Republic of China, Hangzhou 310012, China)
}

\begin{abstract}
Based on the data acquired within the Zhoushan fishing ground and its adjacent area $\left(29^{\circ} 30^{\prime}-31^{\circ} 30^{\prime} \mathrm{N}\right.$, $\left.121^{\circ} 30^{\prime}-124^{\circ} 30^{\prime} \mathrm{E}\right)$, species composition, abundance, and species diversity of zooplankton were sampled by plankton net ( $50 \mathrm{~cm}$ mouth-diameter, $145 \mathrm{~cm}$ net length, $0.505 \mathrm{~mm}$ mesh-aperture) during August 2006. The results identified 93 species (exclude Larvae) from the samples, among which Copepods were the most diverse with 50 species. According to the standard of IRI (the species with IRI above 0.02 were regarded as dominant species in this paper), there were 12 dominant species: Euchaeta concinna, Dolioletta gegenbauri, Sagitta enflata, Sagitta bedoti, Calanus sinicus, Undinula vulgaris, Canthocalanus paupe, Macruran larvae, Diphyes chamissoni, Centropages dorsispinatus, Evadne tergestina, Acartia pacifica. The stations of high abundance were mainly in the southern part and oceanic sea, and low in the northern and near shore waters. Zooplankton in the Zhoushan fishing ground and its adjacent area exhibited high in evenness (0.70), high species number and high diversity indices (4.98). By hierarchical cluster analysis and non-metric multidimensional scaling (MDS) assisted analyzing, zooplankton in Zhoushan fishing ground and its adjacent area could be formed into three assemblages joining at a distance of $17.13 \%$. The biota-environment matching (BIOENV) analysis
\end{abstract}

收稿日期：2009-07-02; 接受日期：2009-11-04

基金项目：国家自然科学基金项目（30970464）；浙江省科技厅项目（2006C23051）

*通讯作者（Corresponding author）, E-mail: cgyu@zjou.net.cn

第一作者简介: 陈小庆 (1984-), 女, 汉族, 浙江人, 在读硕士研究生。主要从事渔业资源及渔业生态学研究。E-mail:wychenxiaoqing@163.com 
showed that the abundance of zooplankton was correlated closely not only to salinity, nitrate, silicate, but also to the Cd and $\mathrm{Pb}$.

Key words: Zooplankton; Community structure; Cluster analysis; Zhoushan fishing ground and its adjacent area; Summer

舟山渔场位于长江口和钱塘江口, 其范围为 $29^{\circ} 30 \sim 31^{\circ} 00^{\prime} \mathrm{N}, 125^{\circ} 00^{\prime} \mathrm{E}$ 以西海区, 面积约为 5.3 $\mathrm{km} \times 104 \mathrm{~km}$, 水深一般为 $20 \sim 40 \mathrm{~m}$, 年间平均表层 水温为 $16 \sim 20.1{ }^{\circ} \mathrm{C}$ 、平均表层盐度为 $12.8 \sim 33.2$ 。 在这里, 由于有长江、钱塘江两大江河的大量径流 注入, 给舟山渔场带来丰富的营养盐, 加上该海区 岛屿众多, 海水交换充分, 浮游植物大量繁殖, 浮 游动物种类繁多, 其种群动态变化不仅可能影响许 多鱼类和其他海洋生物资源的群体数量, 而且在海 洋生态系统中占有非常重要的地位（Shen \& Shi, 2003 )。此外, 浮游动物与海流、水系、渔场相关

(Xu \& Chen, 1989; Chen \& Xu, 1990; Chen et al, 1995; Yang et al, 1999a, b, 2000; He \& Yang, 1990, 1993 ), 有些种类还可成为良好的环境变化指示种。 关于东海近海渔场的浮游动物调查研究, 早在 20 世纪 60 年代初, 开展全国海洋渔业资源普查时就 曾做过调查, 之后徐兆礼等在研究东海和黄海南部 浮游动物时也曾对舟山渔场邻近海域浮游动物进
行过较多研究 (Chen et al, 2003; Guo et al, 2003; Xu et al，1999，2003，2004; Xu，2008，2009), 但多数局限于种类和数量分布或某一类群的研究, 而对舟山渔场及邻近海域浮游动物的生物多样性 等群落结构特征的研究涉及较少。为此, 本文根据 2006 年 8 月在舟山渔场及邻近海域开展海洋生态系 统综合调查所获得的浮游动物资料, 研究了该调查 海域浮游动物的种类组成、数量分布以及生物多样 性, 以了解舟山渔场及邻近海域浮游动物的群落结 构特征，为舟山渔场生物资源的持续利用、生态环 境评价以及生态系统修复提供基础资料。

\section{1 材料和方法}

\section{1 数据来源}

数据取自 2006 年 8 月(夏)租用“浙定渔 11132” 号渔船在舟山渔场及邻近海域 $\left(29^{\circ} 30^{\prime} \sim 31^{\circ} 30^{\prime} \mathrm{N}\right.$, $124^{\circ} 30^{\prime} \mathrm{E}$ 以西) 开展海洋生态系统综合调查所获得 的浮游动物调查资料, 共设 20 个调查站位（图 1)。

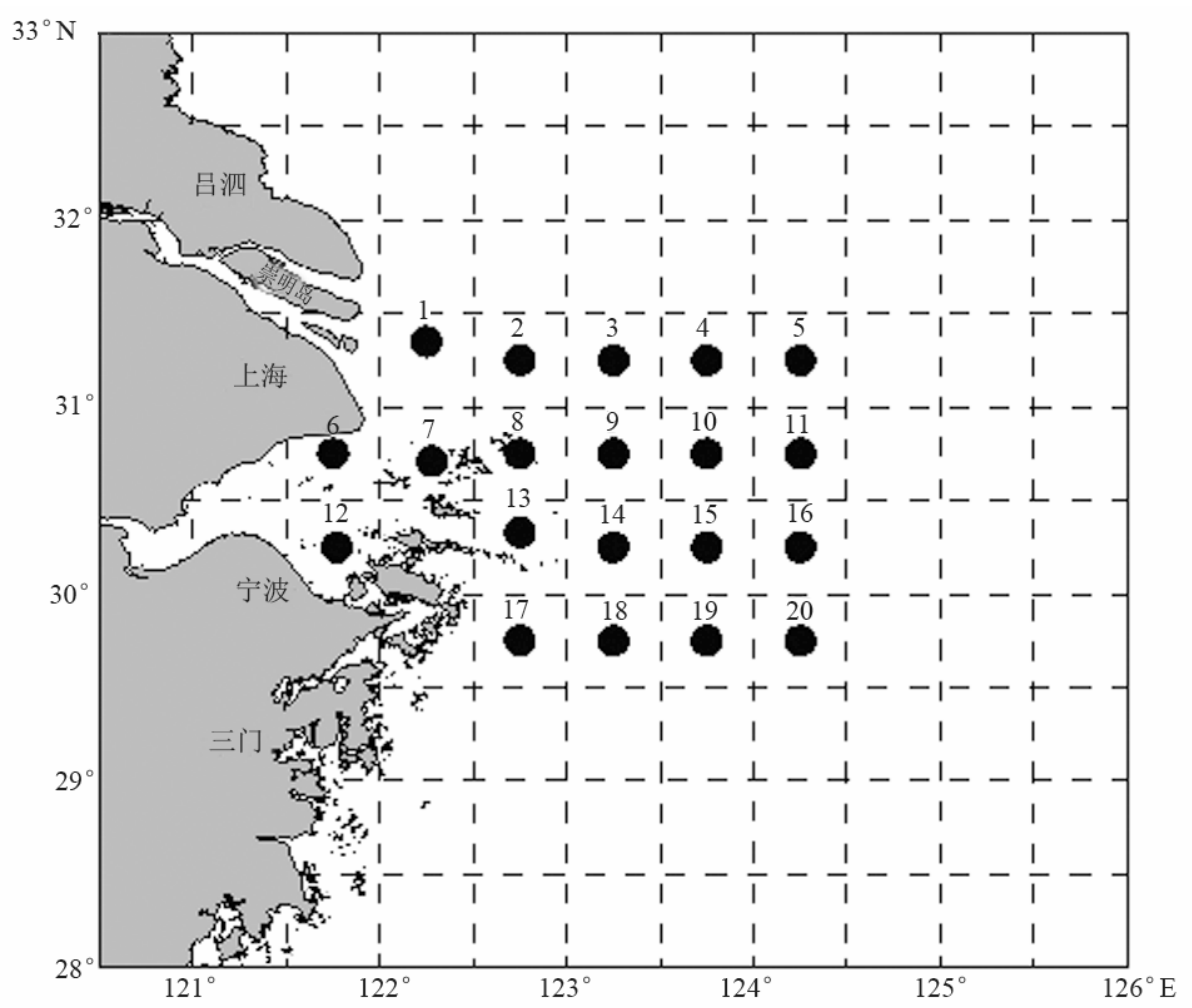

图 1 站位分布图（・）

Fig. 1 The sampling stations $(\bullet)$ 
样品采集用浅水 I 型浮游生物网(口径 $50 \mathrm{~cm}$ 、 笁绢 CQ14、孔径 $0.505 \mathrm{~mm}$ ), 自海底至海面垂直拖 曳采集。样品采集和标本处理均按照《海洋调查规 范一海洋生物调查》(GB12763.6-91) 进行。所获 标本经 5\%福尔马林溶液固定后, 带回实验室进行 分类、鉴定和计数。

\section{2 数据分析方法}

\subsection{1 优势度计算 优势种优势度:}

$$
Y=\frac{n_{i}}{N} \times f_{i}
$$

式中, $\mathrm{Y}$ 为优势度, $n_{i}$ 为第 $i$ 种浮游动物的个体数, $N$ 为浮游动物总个体数, $f_{i}$ 为第 $i$ 种浮游动物在各站位 出现的频率，优势度由Excel计算得到。

\subsection{2 生物多样性分析 生物多样性计算方法如}

下: (1) Margalef 的种类丰富度指数:

$$
D=(S-1) / \log _{2} N
$$

式中, $D$ 为浮游动物种类丰富度指数, $S$ 为浮游动 物总的种类数, $N$ 为所有浮游动物总的个体数。

(2) Shannon-Wiener 多样性指数:

$$
H^{\prime}=-\sum_{i=1}^{S} P_{i} \log _{2} P_{i}
$$

式中, $H^{\prime}$ 为浮游动物种类多样性指数, $P_{i}$ 为第 $i$ 种浮 游动物的个数与总个体数的比值, $S$ 为浮游动物种 数。

(3) Pielou均匀度指数: $J^{\prime}=H^{\prime} / \log _{2} S$

式中, $S$ 为浮游动物种数。

1.2.3 相似性聚类分析 进行相似性聚类分析的 种类名录是这样得到的, 即删除在总体中相对丰度 小于 $1 \%$ 的种, 但保留其中在任一站位相对丰度大 于 $3 \%$ 的种。这样做的目的是为了减少机会种对群
落结构的干扰, 然后用 PRIMER 软件包对群落结构 进行分析（Clarke \& Warwick，1994）。

多样性指数的计算以及相似性聚类、标序分析 和生物-环境匹配分析 (biota-environment matching, BIOENV) 均用 PRIMER5.0 统计软件包。丰度数据 通过二次方根标准化, 在计算 Bray-Curtis 相似性系 数的基础上，用非参数多维标序技术 (MDS) 作二 维标序。检验 MDS 分析结果的好坏用胁强系数 （Stress）来衡量，根据 Khalaf \& Kochzius（2002） 研究, 认为 Stress $<0.2$ 时, 可用 MDS 的二维点图 表示, 其图形有一定的解释意义, 当 Stress $<0.1$ 时, 可以认为是一个好的排序, 当 Stress $<0.05$ 时, 即 具有很好的代表性。本文的聚类（CLUSTER）按 此原则进行分析。

在结合环境因子分析中，首先对环境因子进行 数据的标准化, 在此基础上计算 Nornmalised Euclidean 距离得到不相似性矩阵, 再与浮游动物 的丰度的相似性矩阵作 BIOENV 分析, 得出环境因 子与浮游动物群落结构的相关系数。平面分布图均 采用 Surfer 8.0 软件绘制。

\section{2 结 果}

\section{1 种类组成}

根据本次调查采集的浮游动物样品, 已鉴定到 种的浮游动物共有 93 种 (不包含浮游幼虫)。其中 桡足类占绝对优势，共有 50 种，其次为水螅水母 类，共有 11 种，此外，浮游螺类、樱虾类、毛颚 类各有 4 种，管水母类、端足类各有 3 种，枝角类、 介形类、磷虾类、被囊类各有 2 种，原生动物、栉 水母类、浮游多毛类、头足类、糠虾类、十足类各 有 1 种（表 1 )。

表 1 舟山渔场及邻近海域浮游动物的种类组成

Tab. 1 Zooplankton species composition in Zhoushan fishing ground and its adjacent area

\begin{tabular}{llll}
\hline 序号 & \multicolumn{1}{c}{ 种类 Species } & 序号 & \multicolumn{1}{c}{ No. } \\
NO. & No类 Species \\
\hline I & 原生动物 Protozoa & 46 & 异尾宽水蚤 Temora discaudata \\
1 & 泡抱球虫 Globigerina bulloides & 47 & 雉形宽水蚤 Temora turbinata \\
II & 水螅水母类 Hydromedusae & 48 & 墨氏胸刺水蚤 Centropages mcmurrichi \\
2 & 不列颠高手水母 Bougainvillia britannica & 49 & 哲胸刺水蚤 Centropages calaninus \\
3 & 双手水母 Amphinema dinema & 50 & 背针胸刺水蚤 Centropages dorsispinatus \\
\hline
\end{tabular}


(接上表)

\begin{tabular}{|c|c|c|c|}
\hline $\begin{array}{l}\text { 序号 } \\
\text { NO. }\end{array}$ & 种类 Species & $\begin{array}{l}\text { 序号 } \\
\text { NO. }\end{array}$ & 种类 Species \\
\hline 4 & 澳洲多管水母 Aequorea australis & 51 & 叉胸刺水蚤 Centropages furcatus \\
\hline 5 & 半球美螅水母 Phialidium hemisphaericum & 52 & 奥氏胸刺水蚤 Centropages orsinii \\
\hline 6 & 薮枝水母属 Obelia sp. & 53 & 中华胸刺水蚤 Centropages sinensis \\
\hline 7 & 卡拟杯水母 Phialella carolinae & 54 & 伯氏平头水蚤 Candacia bradyi \\
\hline 8 & 四叶小舌水母 Liriope tetraphylla & 55 & 小长足水蚤 Calanopia minor \\
\hline 9 & 半口壮丽水母 Aglaura hemistoma & 56 & 尖刺唇角水蚤 Labidocera acuta \\
\hline 10 & 四手筐水母 Aegina citrea & 57 & 双刺唇角水蚤 Labidocera bipinnata \\
\hline 11 & 八手筐水母 Aeginura grimaldii & 58 & 后截唇角水蚤 Labidocera detruncata \\
\hline 12 & 两手筐水母 Solmundella bitentaculata & 59 & 真刺唇角水蚤 Labidocera euchaeta \\
\hline III & 管水母类 Siphonophora & 60 & 小唇角水蚤 Labidocera minuta \\
\hline 13 & 华丽盛装水母 Agalma elegans & 61 & 左突唇角水蚤 Labidocera sinilobata \\
\hline 14 & 双生水母 Diphyes chamissonis & 62 & 阔节角水蚤 Pontella fera \\
\hline 15 & 五角水母 Muggiaea atlantica & 63 & 羽小角水蚤 Pontellina plumata \\
\hline IV & 栉水母类 Ctenophora & 64 & 钝简角水蚤 Pontellopsis yamadae \\
\hline 16 & 球形侧腕水母 Pleurobrachia globosa & 65 & 丹氏纺锤水蚤 Acartia danae \\
\hline $\mathrm{V}$ & 浮游多毛类 Pelagic Polychaeta & 66 & 太平洋纺锤水蚤 Acartia pacifica \\
\hline 17 & 箭蚕 Sagitella kowalewskii & 67 & 细长腹剑水蚤 Oithona attenuata \\
\hline VI & 浮游螺类 Pelagic Gastropod & 68 & 拟长腹剑水蚤 Oithona similis \\
\hline 18 & 胖虫琥螺 Limacina inflata & 69 & 丽隆剑水蚤 Oncaea venusta \\
\hline 19 & 马蹄虫琥螺 Limacina trochiformis & 70 & 黑点叶剑水蚤 Sapphirina nigromaculata \\
\hline 20 & 尖笔帽螺 Creseis acicula & 71 & 奇浆剑水蚤 Copilia mirabilis \\
\hline 21 & 芽笔帽螺 Creseis virgula & 72 & 近缘大眼剑水蚤 Corycaeus affinis \\
\hline VII & 头足类 Cephalopod & 73 & 太平洋大眼剑水蚤 Corycaeus pacificus \\
\hline 22 & 双喙耳乌贼 Sepiola birostrata & 74 & 美丽大眼剑水蚤 Corycaeus speciosus \\
\hline VIII & 枝角类 Cladocera & 75 & 挪威小毛猛水蚤 Microsetella norvegica \\
\hline 23 & 鸟㗒尖头溞 Penilia avirostris & 76 & 尖额真猛水蚤 Euterpina acutifrons \\
\hline 24 & 肥胖三角溞 Evadne tergestina & $\mathrm{XI}$ & 糠虾类 Mysidacea \\
\hline IX & 介形类 Ostracoda & 77 & 长额刺糠虾 Acanthomysis longirostris \\
\hline 25 & 尖尾海茧 Cypridina acuminata & XII & 端足类 Amphipoda \\
\hline 26 & 针刺真浮萤 Euconchoecia aculeata & 78 & 细长脚虫戎 Themisto gracilipes \\
\hline$X$ & 桡足类 Copepoda & 79 & 裂傻蛮虫戎 Lestrigonus schizogeneios \\
\hline 27 & 中华哲水蚤 Calanus sinicus & 80 & 克氏尖头虫戎 Oxucephalus clausi \\
\hline 28 & 瘦新哲水蚤 Neocalanus gracilis & XIII & 磷虾类 Euphausiacea \\
\hline 29 & 细角新哲水蚤 Neocalanus tenuicornis & 81 & 中华假磷虾 Pseudeuphausia sinica \\
\hline 30 & 微刺哲水蚤 Canthocalanus pauper & 82 & 隆柱鳌磷虾 Stylocheiron carinatum \\
\hline 31 & 小哲水蚤 Nannocalanus minor & XIV & 樱虾类 Sergestinae \\
\hline 32 & 普通波水蚤 Undinula vulgaris & 83 & 日本毛虾 Acetes japonicus \\
\hline 33 & 强真哲水蚤 Eucalanus crassus & 84 & 汗森荣虾 Lucifer hanseni \\
\hline
\end{tabular}




\begin{tabular}{|c|c|c|c|}
\hline $\begin{array}{c}\text { 序号 } \\
\text { NO. }\end{array}$ & 种类 Species & $\begin{array}{c}\text { 序号 } \\
\text { NO. }\end{array}$ & 种类 Species \\
\hline 34 & 亚强真哲水蚤 Eucalanus subcrassus & 85 & 中型莹虾 Lucifer intermedius \\
\hline 35 & 克氏长角哲水蚤 Mecynocera clausi & 86 & 正型荣虾 Lucifer typus \\
\hline 36 & 针刺拟哲水蚤 Paracalanus aculeatus & $\mathrm{XV}$ & 十足类 Decapoda \\
\hline 37 & 强额拟哲水蚤 Paracalanus crassirostris & 87 & 细鳌虾 Leptochela gracilis \\
\hline 38 & 小拟哲水蚤 Paracalanus parvus & XVI & 毛颚类 Chaetognatha \\
\hline 39 & 隆线拟哲水蚤 Calanoides carinatus & 88 & 百陶箭虫 Sagitta bedoti \\
\hline 40 & 驼背隆哲水蚤 Acrocalanus gibber & 89 & 肥胖箭虫 Sagitta enflata \\
\hline 41 & 弓角基齿哲水蚤 Clausocalanus arcuicornis & 90 & 拿卡箭虫 Sagitta nagae \\
\hline 42 & 长尾基齿哲水蚤 Clausocalanus furcatus & 91 & 美丽箭虫 Sagitta pulchra \\
\hline 43 & 精致真刺水蚤 Euchaeta concinna & XVII & 被囊类 Tunicata \\
\hline 44 & 平滑真刺水蚤 Euchaeta plana & 92 & 长尾住囊虫 Oikopleura longicauda \\
\hline 45 & 缘齿厚壳水蚤 Scolecithrix nicobarica & 93 & 软拟海樽 Dolioletta gegenbauri \\
\hline
\end{tabular}

\section{2 优势种}

Xu \& Chen (1989) 在研究东黄海浮游动物优 势种时, 将优势度 $Y \geqslant 0.02$ 时的浮游动物确定为优 势种。本文按此标准进行分析, 结果得出夏季调查 海域优势种共有 12 种, 依次为精致真刺水蚤 (Euchaeta concinna) 、软拟海樽 (Dolioletta gegenbauri)、肥胖箭虫 (Sagitta enflata)、百陶箭虫

(Sagitta bedoti)、中华哲水蚤（Calanus sinicus）、 普通波水蚤 (Undinula vulgaris)、微刺哲水蚤

(Canthocalanus paupe)、长尾类幼虫 (Macruran larvae)、双生水母 (Diphyes chamissonis)、背针胸 刺水蚤 (Centropages dorsispinatus)、肥胖三角溞
(Evadne tergestina)、太平洋纺锤水蚤（Acartia pacifica)，这些种类大多数为桡足类（表 2)。它们 的丰度占浮游动物总丰度的 $67.47 \%$ 。

\section{3 丰度的平面分布}

调查海区浮游动物丰度分布范围为 $3.33 \sim 872$ ind. $/ \mathrm{m}^{3}$, 其中, 以 16 号站位的丰度最大, 1 号站位 的最小，两者相差 262 倍。夏季舟山渔场及邻近海 域浮游动物平面分布呈现南部高、北部低、近岸高、 外海低的特征（图 2)。

根据浮游动物种类丰度与环境因子的 BIOENV 相关分析，显示盐度、硝酸盐、硅酸盐、磷酸盐等 均是与种类丰度密切相关的环境因子（表 3 )。

表 2 舟山渔场及邻近海域浮游动物优势种的优势度

Tab.2 Dominant species of zooplankton in Zhoushan fishing ground and its adjacent area

\begin{tabular}{lc}
\hline \multicolumn{1}{c}{ 优势种 Dominant species } & 优势度 Dominance \\
\hline 精致真刺水蚤 Euchaeta concinna & 0.09 \\
软拟海樽 Dolioletta gegenbauri & 0.09 \\
肥胖箭虫 Sagitta enflata & 0.06 \\
百陶箭虫 Sagitta bedoti & 0.04 \\
中华哲水蚤 Calanus sinicus & 0.03 \\
普通波水蚤 Undinula vulgaris & 0.03 \\
微刺哲水蚤 Canthocalanus pauper & 0.03 \\
长尾类幼虫 Macruran larvae & 0.03 \\
双生水母 Diphyes chamissonis & 0.02 \\
背针胸刺水蚤 Centropages dorsispinatus & 0.02 \\
肥胖三角溞Evadne tergestina & 0.02 \\
太平洋纺锤水蚤 Acartia pacifica & 0.02 \\
\hline
\end{tabular}




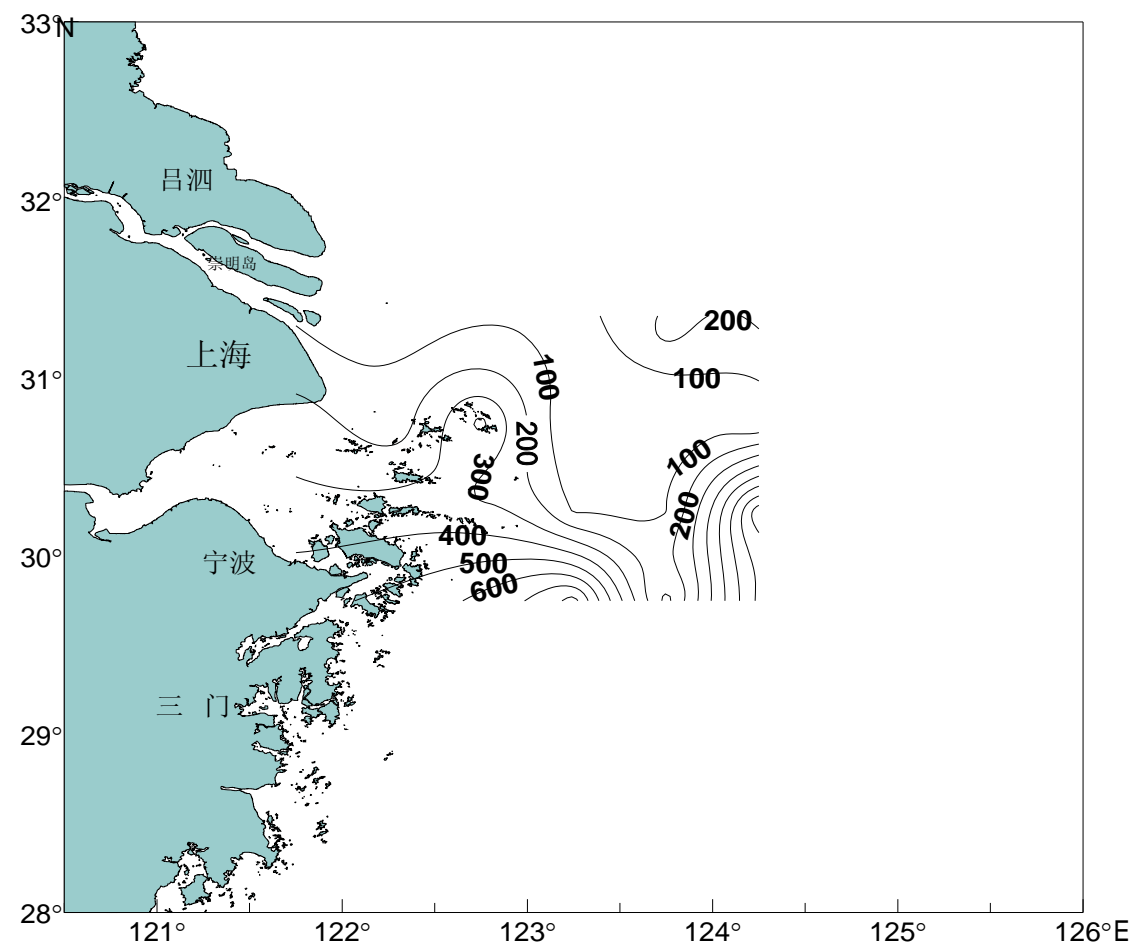

图 2 舟山渔场及邻近海域浮游动物丰度平面分布

Fig. 2 The horizontal distribution of zooplankton in Zhoushan fishing ground and its adjacent area

表 3 舟山渔场及邻近海域浮游动物种类丰度与环境因子 Spearman 相关系数

Tab. 3 Spearman correlation coefficients between the species abundance of the zooplankton and the environmental factors

\begin{tabular}{lcccccccc}
\hline 环境因子 Environmental factors & $\begin{array}{c}\text { 盐度 } \\
\text { Salinity }\end{array}$ & $\begin{array}{c}\text { 硝酸氮 } \\
\text { Nitrate }\end{array}$ & $\begin{array}{c}\text { 硅酸盐 } \\
\text { Silicate }\end{array}$ & $\begin{array}{c}\text { 磷酸盐 } \\
\text { Phosphate }\end{array}$ & $\begin{array}{c}\text { 酸碱度 } \\
\mathrm{pH}\end{array}$ & $\begin{array}{c}\text { 水温 } \\
\text { Temperature }\end{array}$ & $\begin{array}{c}\text { 镉 } \\
\mathrm{Cr}\end{array}$ & $\begin{array}{c}\text { 铅 } \\
\mathrm{Pb}\end{array}$ \\
\hline 相关系数 Correlation coefficients & 0.57 & 0.52 & 0.52 & 0.30 & 0.25 & -0.03 & -0.22 & -0.24 \\
\hline
\end{tabular}

\section{4 生物多样性指数}

表 4 列出了 20 个站位的生物多样性分析结果, 从表中可以看出, Shannon-Wiener 指数 $\left(H^{\prime}\right)$ 的分布 范围为 $1.83 \sim 4.45$, 平均为 $(3.30 \pm 0.78)$; 均匀度指 数 $\left(J^{\prime}\right)$ 为 0.70 , 总体 Shannon-Wiener 指数 $\left(H^{\prime}\right)$ 为 4.98 。 由于调查海域浮游动物的种类数较多, 且具有较高 的均匀度, 因此其生物多样性指数较高。

\section{5 聚类、排序结果}

为了减少机会种对群落结构的干扰, 将在总体 中相对丰度小于 $1 \%$ 的种删除, 但保留其中在任一 站位相对丰度大于 $3 \%$ 的种, 结果得出满足条件的 有 46 种, 对这 46 种浮游动物进行丰度相似性矩阵 聚类和 MDS 分析, 结果如图 3 所示。从图中可以 看出, 可将调查海域的浮游动物分为 $\mathrm{A} 、 \mathrm{~B} 、 \mathrm{C}$ 三 个组群。 $\mathrm{A}$ 组群与 $\mathrm{B} 、 \mathrm{C}$ 组群之间的相似度为 $10.76 \%, B 、 C$ 相似度为 $17.13 \%$ 。 $A$ 组群包含位于
长江口附近的 1 号站位; $\mathrm{B}$ 组群包含位于杭州湾内 的 6、7、12 号站位, $\mathrm{C}$ 组群包含了 $122^{\circ} 30^{\prime} \mathrm{E}$ 以东 的所有站位。对应的非参数多变量排序结果中 0.1 $<$ Stress $<0.2$ 表明可用二维点图表示, 其图形有一 定的解释意义。相似性分析（ANOSIM）表明群聚 间的种类组成呈显极著性差异（表 5)。

\section{3 讨 论}

桡足类是夏季舟山渔场及邻近海域的主要生 物类群。在已鉴定出的 93 种浮游动物中，桡足类 共有 50 种, 占 $53.76 \%$; 优势种也多属于这个类群, 如桡足类的精致真刺水蚤、普通波水蚤、中华哲水 蚤和微刺哲水蚤等, 这与长江口浮游动物的组成相 似 (Ji \& Ye, 2006)。此外, 水螅水母类种类也较 多, 有 11 种, 占 $11.83 \%$ 。水螅水母类具有随波逐 流的生活习性, 是东海水团分布态势的重要指示种 
(Xu，2009）。

夏季舟山渔场及邻近海域浮游动物高丰度区 出现在 $30^{\circ} 30^{\prime} \mathrm{N}$ 以南海域, 即在外海高盐水与沿岸
水相交汇的海域。这与 2000-2002 年长江口水域 浮游动物生物量平面分布特征基本一致（Xu \& Shen，2005）。一般的说，高丰度区分布在不同水

表 4 舟山渔场及邻近海域浮游动物的多样性

Tab. 4 Species diversity of zooplankton in Zhoushan fishing ground and its adjacent area

\begin{tabular}{|c|c|c|c|c|}
\hline $\begin{array}{l}\text { 站位 } \\
\text { Station }\end{array}$ & $\begin{array}{c}\text { 种数 } \\
\text { Number of species }(S)\end{array}$ & $\begin{array}{c}\text { 丰富度指数 } \\
\text { Richness（D） }\end{array}$ & $\begin{array}{l}\text { 均匀度指数 } \\
\text { Evenness }\left(J^{\prime}\right)\end{array}$ & $\begin{array}{c}\text { Shannon-Wiener 多样性指数 } \\
\text { Shannon-Wiener index }\left(H^{\prime}\right)\end{array}$ \\
\hline 1 & 6 & 1.67 & 0.93 & 2.41 \\
\hline 2 & 21 & 2.08 & 0.86 & 3.76 \\
\hline 3 & 31 & 3.22 & 0.63 & 3.13 \\
\hline 4 & 41 & 3.64 & 0.77 & 4.11 \\
\hline 5 & 38 & 3.48 & 0.73 & 3.81 \\
\hline 6 & 15 & 1.27 & 0.47 & 1.83 \\
\hline 7 & 16 & 1.46 & 0.70 & 2.80 \\
\hline 8 & 37 & 3.15 & 0.73 & 3.78 \\
\hline 9 & 25 & 3.68 & 0.85 & 3.96 \\
\hline 10 & 20 & 2.98 & 0.83 & 3.60 \\
\hline 11 & 27 & 3.54 & 0.84 & 3.98 \\
\hline 12 & 22 & 1.84 & 0.53 & 2.37 \\
\hline 13 & 42 & 3.81 & 0.74 & 3.98 \\
\hline 14 & 42 & 4.22 & 0.67 & 3.63 \\
\hline 15 & 31 & 3.07 & 0.60 & 2.95 \\
\hline 16 & 38 & 2.80 & 0.35 & 1.83 \\
\hline 17 & 56 & 4.71 & 0.53 & 3.08 \\
\hline 18 & 44 & 3.56 & 0.72 & 3.91 \\
\hline 19 & 38 & 3.82 & 0.51 & 2.67 \\
\hline 20 & 65 & 4.94 & 0.74 & 4.45 \\
\hline
\end{tabular}
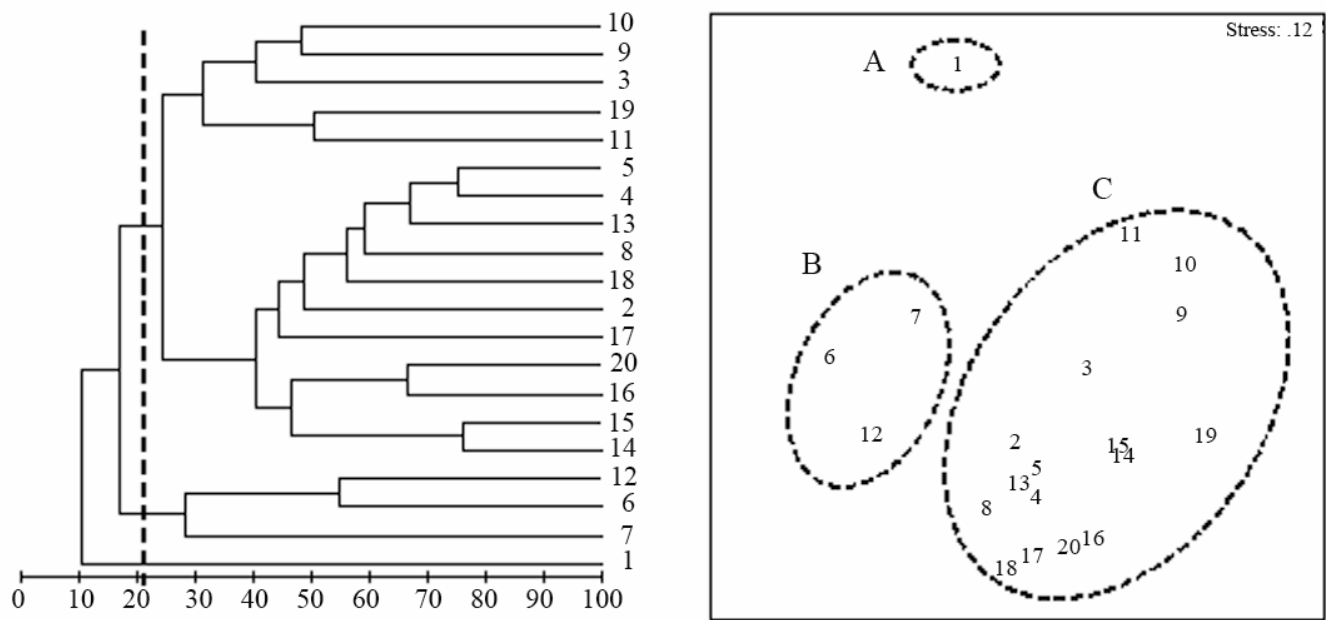

图 3 舟山渔场及邻近海域浮游动物群落结构的聚类分析和非参数多变量标序

Tab. 3 Cluster and MDS Ordination of zooplankton in Zhoushan fishing ground and its adjacent area 
表 5 不同组群间 ANOSIM 的显著性检验 Tab. 5 One-way ANOSIM test between different groups

\begin{tabular}{lccc}
\hline 组群 Group & A & B & C \\
\hline A & 1 & & \\
B & 1.00 & 1 & \\
C & 0.98 & 0.71 & 1 \\
\hline
\end{tabular}

系相交汇区域的两侧，而在不同水系相交汇区域内 的丰度较低, 夏季调查海域浮游动物丰度平面分布 也显示了这一特征。

BIOENV 相关分析表明, 调查海域夏季浮游动 物的丰度与表层海水的盐度、硝酸氮和硅酸盐的相 关性皆高于其他环境因子。外海高盐水与沿岸水相 交汇的海域营养盐丰富, 这可能是导致该海域浮游 动物高丰度区的一个重要原因。夏季, 沿岸水温与 外海基本相同, 调查海域水温较高 (表层平均水温

\section{参考文献:}

Chen YQ, Xu ZL, Wang YL, Hu FX, Han MB, Yan HC. 1995. An ecological study on zooplankton in plume front zone of Changiiang River Estuary Area II species composition, community structure and indicator species [J]. J Fish Sci Chn, 2 (1): 59-63 [陈亚㫿, 徐兆礼, 王云龙, 胡方西, 韩明宝, 严宏昌. 1995. 长江口河口锋区浮游动物 生态研究 II 种类组成、群落结构、水系指示种. 中国水产科学, 2 (51): 59-63]

Chen YQ, Xu ZL, Zhao WW. 2003. Study on ecology of meso-small pelagic copepods in the Southern Yellow Sea and the East China Sea III. Dominant species [J]. J Fish Chn, 27 (Suppl): 1-8. 陈亚翟, 徐兆礼, 赵文武. 2003. 黄海南部及东海中小型浮游桡足类生态学研究 III. 优势种. 水产学报, 27 (增刊): 16-22.]

Chen YQ, Xu ZL. 1990. Ecological characteristics of zooplankton in fleeding ground of mackerel and scads from the Southern Yellow Sea and East China Sea [J]. Chn J Appl Ecol, 1(4): 327-332.[陈亚㫿, 徐兆 礼. 1990. 南黄海、东海鲐鮻鱼索覀渔场浮游动物分布特征的研究. 应用生态学报, 1(4): 327-332.]

Clarke KR, Warwick RM. 1994. Change in Marine Communities: an Approach to Statistical Analysis and Interpretation [M]. Plymouth, UK: Plymouth Marine Laboratory.

Guo PY, Shen HT, Liu AC, Wang JH, Yang YL. 2003. The species composition, community structure and diversity of zooplankton in Changjiang estuary [J]. Acta Ecol Sin, 23 (5): 892-899. [郭沛勇, 沈焕 庭, 刘阿成, 王金辉, 杨元利. 2003. 长江口浮游动物的种类组成、 群落结构及多样性. 生态学报, 23 (5): 892-899.]

He DH, Yang GM. 1990. Distribution characteristic of pelagic copepods in Kuroshiro Mainstream and its adjacent areas in spring of 1986. I Horizontal distribution [C]// Essays on investigation of Kuroshio Contents: The first part. Beijing: Ocean Press, 265-294.[何德 华, 杨关铭. 1990. 1986. 年春季东海黑潮及其邻近海区的浮游动物 桡足类的分布特征 I 平面分布. 黑潮调查研究论文选. 第一集. 北 京: 海洋出版社, 265-294.]

He DH, Yang GM. 1993. Distribution of indicative pelagic copepods in
为 $28.14{ }^{\circ} \mathrm{C}$ ) 且均匀, 因此表层水温对浮游动物的 丰度基本上没有影响。此外, 浮游动物的丰度与表 层海水中重金属（镉、铅）的含量存在着一定的负 相关性。

本次调查海域的水文环境复杂，多种不同性质 的水系相交汇, 浮游动物组成也体现了这种性质。 对浮游动物群落聚类分析结果显示, 可将调查海域 的浮游动物分为 $\mathrm{A} 、 \mathrm{~B} 、 \mathrm{C}$ 三个组群。 $\mathrm{A} 、 \mathrm{~B}$ 组群分 别位于长江口和杭州湾附近, 种类较少, 受沿岸冲 淡水影响主要以真刺唇角水蚤、背针胸刺水蚤和太 平洋纺軓水蚤等近岸低盐种类为主。 $\mathrm{C}$ 组群位于 $122^{\circ} 30^{\prime} \mathrm{E}$ 以东海域, 在夏季, 该海域受外海高温高 盐水影响, 主要以精致真刺水蚤、肥胖箭虫等外海 高温高盐种类为主, 同时, 由于夏季调查海域的大 部分站位分布在长江和钱塘江冲淡水影响区域, 因 此也出现有近岸低盐种类。

Kuroshiro Contents [C]// Essays on investigation of Kuroshio Contents: The five part. Beijing: Ocean Press, 421-435.[何德华, 杨关铭. 1993. 指示性浮游桡足类在东海黑潮域的分布. 黑潮调查研究论文选. 第 五集. 北京: 海洋出版社, 421-435.]

Ji HH, Ye SF. 2006. Ecological distribution characteristics of zooplankton and its relationship with environmental factors in the Changjiang River estuary [J]. Mar Sci, 30 (6): 23-30. [ 纪焕红, 叶属峰. 2006. 长江口 浮游动物生态分布特征及与环境的关系. 海洋科学, 30 (6): 23-30.]

Khalaf MA, Kochzius M. 2002. Change in trophic community structure of shore fishes at an industrial site in the Gulf of Aqaba Red Sea [J]. Mar Ecol Prog Ser, (239): 287-299.

Shen GY, Shi BZ. 2003. Marine Ecology [M]. Beijing: Science Press, 153-183. [沈国英, 施并章. 2003. 海洋生态学. 北京: 科学出版社, 153-183.]

$\mathrm{Xu}$ ZL, Chao M, Chen YQ. 2004. Distribution characteristics of zooplankton biomass in the East China Sea[J]. Acta Ocean Sin, 26 (3): 93-101[徐兆礼, 昆 敏, 陈亚翟. 2004. 东海浮游动物生物量分布 特征. 海洋学报, 26 (3): 93-101.]

Xu ZL, Chen YQ. 1989. Aggregated intensity of dominant species of zooplankton in autumn in the East China Sea and Yellow Sea [J]. Chn J $E c o l, 8$ (4): 13-15. [徐兆礼, 陈亚㫿. 1989. 东黄海秋季浮游动物优 势种聚集强度与鲐鱼渔场的关系. 生态学杂志, 8 (4): 13-15.]

Xu ZL, Shen XQ. 2005. Zooplankton biormass and its variation in water near Changjiang estuary[J]. Resour Environ Yangze Basin, 14 (3): 282-286. [徐兆礼, 沈新强. 2005. 长江口水域浮游动物生物量及年间 变化. 长江流域资源与环境, 14 (3): 282-286.]

Xu ZL, Wang R, Chen YQ. 2003. Study on ecology of meso-small pelagic copepods in the Southern Yellow Sea and the East China Sea I . Quantitative distribution [J]. J Fish Chn, 27 (Suppl): 1-8. [徐兆礼, 王 荣, 陈亚㫿. 2003. 黄海南部及东海中小型浮游桡足类生态学研究 I. 数量分布, 水产学报, 27 (增刊): 1-8.]

Xu ZL, Wang YL, Bai XM, Chen YQ. 1999. An ecological study on zooplankton in the Chang estuary [J]. J Fish Sci Chn, 6 (5): 55-58. [徐 
兆礼, 王云龙, 白雪梅, 陈亚翟. 1999. 长江口浮游动物生态研究. 中国水产科学, 6 (5): 55-58.]

Xu ZL. 2008. Enviromental adaptation of Pelagic polychaeta in the East China Sea [J]. Chn J Appl Envron Biol, 14 (1): 53-58. [徐兆礼. 2008. 东海浮游多毛类环境适应分析. 应用与环境生物学报, 14 (1): 53-58.]

Xu ZL. 2009. Water environment adaptability and ecological grounds of Hydoidomedusae in East China Sea [J]. Chn J App Ecol, 20 (1): 177-184. [徐兆礼. 2009. 东海水螅水母环境适应与生态类群. 应用 生态学报, 20 (1): 177-184.]

Yang GM, He DH, Wang CS, Miao YT, Yu HH. 1999. Study on the biological oceanographic characteristics of planktonic copepods in the waters north of Taiwan, China I .Abundance distribution [J]. Acta Ocean Sin, 21 (4): 78-86. [杨关铭, 何德华, 王春生, 苗育田, 于洪
华. 1999. 台湾以北海域浮游桡足类生物海洋学特征的研究 I. 数 量分布. 海洋学报, 21 (4): 78-86.]

Yang GM, He DH, Wang CS, Miao YT, Yu HH. 1999b. Study on the biological oceanographic characteristics of planktonic copepods in the waters north of Taiwan II. Community characteristics [J]. Acta Ocean Sin, 21 (6): 72-80. [杨关铭，何德华，王春生，苗育田，于洪华. 1999 台湾以北海域浮游桡足类生物海洋学特征的研究 II. 群落特征. 海 洋学报, 21 (6): 72-80.]

Yang GM, He DH, Wang CS, Miao YT, Yu HH. 2000. Study on the biological oceanographic characteristics of planktonic copepods in the waters north of Taiwan: III. Indicator species [J]. Acta Ocean Sin, 22 (1): 93-101. [杨关铭, 何德华, 王春生, 苗育田, 于洪华. 2000. 台湾 以北海域浮游桡足类生物海洋学特征的研究: III. 指示性种. 海洋 学报, 22 (1): 93-101.]

（上接第 76 页）

\section{《动物学研究》诚谢 2009 年度审稿人}

\begin{tabular}{|c|c|}
\hline 梁旭方 & 暨南大学生命科学技术学院 \\
\hline 梁子才 & $\begin{array}{c}\text { 北京大学分子医学研究所 } \\
\text { 核酸技术实验室 }\end{array}$ \\
\hline 刘榜 & 华中农业大学遗传育种系 \\
\hline 刘焕章 & 中科院水生生物所 \\
\hline 刘廼发 & 兰州大学生命科学学院 \\
\hline 刘少军 & 湖南师范大学生命科学学院 \\
\hline 刘振生 & 中国科学院动物研究所 \\
\hline 刘至治 & 上海海洋大学 \\
\hline 路纪琪 & 郑州大学生物工程系 \\
\hline 罗静 & 云南大学生命科学学院 \\
\hline 龙勇诚 & 大自然保护协会 \\
\hline 马恩波 & 山西大学应用生物所 \\
\hline 马杰 & 华东师范大学 \\
\hline 马志军 & 复旦大学生物多样性研究所 \\
\hline 缪炜 & 中国科学院水生生物所 \\
\hline 苪荣 & 南京农业大学动物医学院 \\
\hline 宋延龄 & 中国科学院动物研究所 \\
\hline 谭德勇 & 云南大学生命科学学院 \\
\hline 唐静亮 & 浙江省舟山海洋生态监测站 \\
\hline 唐琼英 & 中国科学院水生生物所 \\
\hline 唐文乔 & 上海海洋大学生命学院 \\
\hline 童春富 & 华东师范大学河口海岸学 \\
\hline
\end{tabular}

国家重点实验室

汪亚平 中科院水生生物所

王德华中国科学院动物研究所

王小明华东师范大学生命科学学院

王义权厦门大学生命科学学院

王艺否集美大学水产生物技术研究所

王毅中国科学院生物物理研究所

王增军南京医科大学第一临床

医学院泌尿外科

温利华加拿大渥太华大学分子细胞

医学研究所

吴孝兵安徽师范大学生命科学学院

向余劲攻 复旦大学生命科学院

向左甫中南林业科技大学生命

科学与技术学院

肖春杰云南大学生命科学学院

肖蘅云南大学生命科学学院

徐基良北京林业大学自然保护区学院

徐兆礼中国水产科学研究院东海

水产研究所

许秀峰昆明医学院第一附属医院精神科

薛俊增杭州师范学院生命科学学院

杨大荣中国科学院西双版纳热带植物园 